Acta Poetica $33 \cdot 2$

JULIO-DICIEMBRE

$2012(125-149)$

\title{
Filosofía entre bastidores: teatralidad, lógica y ritual en India antigua
}

\author{
Juan Arnau
}

El artículo analiza los debates públicos en India antigua, distinguiendo las diferentes modalidades de estas prácticas tal y como aparecen registradas en los compendios de lógica (Nyāyasūtra) y en la literatura médica sánscrita (Carakasamhitā). Se presta una atención especial a una de estas clases de debate, llamada vitandā, donde se permite una dialéctica limitada a la refutación y que desestima la defensa de un punto de vista propio. Este tipo de dialéctica, ejercida por diferentes escuelas de pensamiento en las que la argumentación negativa adquiriría un papel fundamental, encontraría su ámbito de desarrollo en tradiciones religiosas como el budismo madhyamaka y el vedānta advaita. La justificación de estas prácticas, en las que la lógica se representa como en un teatro, dará paso a una filosofía irónica que encuentra muchos puntos de contacto con la filosofía contemporánea.

Palabras clave: Budismo madhyamaka, vitandā, debate, lógica, ironía.

The article analyses the public debates in ancient India, distinguishing the different modalities of these practices as they appear in the compendiums of logic (Nyāyasütra) and in the medical Sanskrit literature (Carakasamhitā). A special attention is paid to one of these kinds of debate, called vitandā, which allows a dialectic limited to refutation and dismissed the defence of the own point of view. This type of dialectic, exercised by different schools of thought in which the negative argument would acquire a fundamental role, would find its scope of development in religious traditions as Madhyamaka Buddhism and Advaita Vedanta. The justification of such practices, in which the logic is represented as in a theatre, will give way to an ironic philosophy which found many points of contact with contemporary thought.

KeYwords: Madhyamaka Buddhism, Vitandā, debate, logic, irony. 

Juan Arnau

Consejo Superior de Investigaciones Cientificas, España

\section{Filosofía entre bastidores: teatralidad, lógica y ritual en India antigua}

\section{Debates en India antigua}

Según una antigua costumbre de India, algunos príncipes y soberanos congregaban periódicamente a pensadores, ascetas y religiosos de diferentes escuelas para discutir alguna cuestión controvertida. Nos ha quedado constancia de algunos de los temas que se debatían. La identidad o diferencia entre el cuerpo y el alma, la vida después de la muerte, el sentido de la existencia, las reglas de comportamiento y algunas cuestiones morales. Aunque los temas de discusión tenían un carácter más metafísico que político, el resultado del debate podía afectar las condiciones de vida de las escuelas en litigio, de modo que el arte de la persuasión adquiriría una gran importancia social y política.

La depuración de los criterios y reglas para determinar un ganador contribuyeron al refinamiento de los procesos formales de inferencia (anumāna) e impulsaron el desarrollo de la lógica, siendo la práctica social del debate y la necesidad de convencer al otro sus precursores. Así, la investigación de la lógica de India antigua pasa por el estudio de las reglas de dichos debates y el análisis de las condiciones bajo las cuales un argumento se consideraba probado y uno de los participantes resultaba derrotado. Los jueces (madhyastha) debían ser, según Śrīharșa, neutrales y rápidos en advertir si alguno de los participantes 
violaba algunas de las reglas del debate, lo que otorgaba inmediatamente la victoria a su oponente.

Muchas de las escuelas filosóficas disponían de manuales de adiestramiento que servían para el entrenamiento de sus discípulos. Los estudiantes se familiarizaban con los diversos modelos de argumentos, los distintos tipos de falacias (hetvabhāsa), los argumentos circulares (cakraka), la identificación rápida de pseudo razones y falsos ejemplos. Los tratados de adiestramiento clasificaban minuciosamente las contradicciones, los trucos y los sofismas (chala) que podían determinar, si eran identificados a tiempo, la derrota del adversario, o que eran utilizados para ganar tiempo o despistar.

Las palabras sánscritas para el debate o la discusión lógica son kathā y vāda. Bimal Krishna Matilal ha ofrecido una descripción de los diferentes tipos de debates que, según la escuela nyāya, se podrían agrupar en tres grandes categorías. ${ }^{1}$ Había un debate amistoso, honesto, donde las razones estaban justificadas, otro hostil, que admitía métodos deshonestos, trucos y otras artimañas, y un tercero en el que una de las partes pretendía solo la refutación de la otra, sin pretender establecer o probar tesis alguna por su parte.

1. va $\bar{a} \boldsymbol{d a}$ (debate, diálogo). Debate amistoso y cordial que usualmente tenía lugar entre maestro y discípulo. El Caraka-samhitā lo denomina sandhāya. Ambos contendientes buscan establecer una verdad, que toma la forma de una proposición (pratijña $\overline{\text { ) }}$ que tiene que ser probada o rechazada. El diálogo presenta una tesis y su antítesis, como cuando se atribuyen a un mismo objeto dos cualidades contradictorias (i.e. el sonido es eterno, el sonido no es eterno). La tesis deberá probarse mediante pruebas y razonamientos (tarka). Cada una de las partes formula el argumento mediante el silogismo de cinco miembros y la tesis probada no deberá contradecir ni los supuestos ni ningún otro principio evidente por sí mismo o de sentido común. En este tipo de debates el que no es capaz de probar su proposición no es censurado ni humillado. No hay

${ }^{1}$ Bimal Krishna Matilal. Perception. An Essay on Classical Indian Theories of Knowledge, Oxford University Press, 1986. También de Matilal: The Character of Logic in India, Jonardon Ganeri y Heeraman Tiwari (ed.), State University of New York Press, 1998. 
vencedor ni vencido, solo una marcha dialogante y jerarquizada (a veces autoritaria) hacia la verdad.

2. jalpa (sofistería, altercado dialéctico). Este segundo tipo de debate no comparte las buenas intenciones del primero. Lo decisivo aquí es la victoria (vijayā), no la verdad. Normalmente tenía lugar entre representantes de escuelas filosóficas rivales. Se permitían toda clase de trucos y ardides dialécticos para confundir al adversario: falsas paridades, pseudo-razones, objeciones banales para ganar tiempo, recursos retóricos, sofismas, etc. Aunque los golpes bajos estaban permitidos, si alguno de los contendientes los identificaba y lograba hacérselo ver a los jueces, estos podían dar por concluido el debate y dictaminar el vencedor. De modo que la simpatía o recelo de los jueces hacia los contendientes podía resultar decisiva. Los Diálogos de lógica (Nyāya-sūtra) listan veintidós situaciones que daban por concluido un debate (nigraha-sthāna), aunque otras fuentes como la Colección de Caraka (Caraka-saṃitāa) o algunos manuales budistas y jainistas listan un número diferente. En este tipo de debates la razón bien fundada no aseguraba la victoria. Las estrategias de intimidación eran frecuentes, uso de abstrusos tecnicismos o referencia a textos con los que el oponente no estaba familiarizado. El nerviosismo o la precipitación también podían jugar malas pasadas a los contendientes, que podían cometer errores en la presentación de su argumento. La teatralidad jugaba también su papel. Udayana apunta que se podía perder tan pronto como se mostrara confusión o aturdimiento. Así, un sofisma que destilara autoridad y que pareciera inteligente podía derrotar a una razón bien fundada expresada con un tono dubitativo en un debate presidido por jueces incompetentes.

3. vitanda (debate de refutación). Se trata de una crítica que pretende mostrar las inconsistencias lógicas del oponente sin establecer ninguna tesis propia. Para que se pudiera dar este tipo de debates una de las partes establecía una tesis, mientras que la otra, el vitandin, se encargaba de refutarla sin proponer tesis alguna, de modo que la impugnación de una tesis no comprometía al impugnador a aceptar la tesis contraria. Este tipo de discusión fue la preferida de los cārvaka (materialistas), los mādhyamika (budistas) y los vedāntin (hinduistas).

El término sánscrito vitaṇdă, cuando se dice de una palabra, de una doctrina o de una proposición, significa falaz, y tiene una connotación 
de frivolidad. Cuando se aplica a una réplica en una argumentación o debate el término tiene dos aspectos. El negativo se podría traducir por "capcioso", eso que hace arrancar al contrincante una respuesta que podría comprometerlo o que favorece el propósito del que la formula. En su aspecto positivo significaría "argumentación negativa". El término tiene algo también de burla fina y disimulada y, como en la ironía, de pretensión de dar a entender algo diferente a lo que se dice. Es precisamente esa distinción entre decir y mostrar la que permite leer a los vitandines como ironistas.

Sin embargo, desde la perspectiva de la escuela nyāya, el debate vitaṇ̂a debía considerarse una subcategoría de jalpa, el altercado dialéctico y tramposo que solo pretende la victoria, aunque, como veremos más adelante, algunos pensadores como Nāgārjuna o Śrī Harṣa defenderían su legitimidad.

Nos encontramos pues con tres modos de la verdad. Uno busca razones justificadas, otro la victoria y el último la falsedad. En el primero, vāda, la verdad exige de la colaboración y de la confianza. En el segundo, jalpa, la verdad requiere de la ambición de victoria, el juego sucio y la falta de escrúpulos. Jalpa expresaría la lucha por el poder, la verdad del poder, mientras que vadā el poder de la verdad. En el tercero, vitaṇ̂a, que es el que más nos va a interesar aquí, la verdad exigía encontrar lo falso. Solidaridad jerarquizada y académica ( $v \bar{a} d a)$, fraude y picaresca intelectual (jalpa) y escepticismo del que piensa que solo el error habla (vitandāa). La misma taxonomía del debate plantea ya numerosas cuestiones. Si fuera cierto que el error se desbarata solo (Borges) no haría falta un debate como vitaṇdā. Aunque en teoría y según los textos canónicos del nyāya, los debates estaban estructurados según estas tres modalidades, es muy probable que se produjeran ingerencias entre uno y otro.

Surge entonces una inevitable cuestión, que los Nyāya-sūtra no eluden. Si hay una verdad y una razón justificada, ¿por qué utilizar falacias o pseudo razones? ¿Qué utilidad tendrían las artimañas y los trucos del debate jalpa para el que busca la verdad? Si el argumento del oponente adolece de algún defecto, bastaría con señalarlo, advertir la falacia o la pseudo razón. Y si no adolece de defecto alguno, bastaría con aceptarlo y reconocer su verdad. Para el que busca la verdad y confía en las po- 
sibilidades de lo discursivo no debería ser necesario utilizar métodos ilegítimos para lograr la victoria, pues la única victoria sería la verdad misma. Las reglas de la lógica (indistinguibles de las del debate) la hacen posible, el camino ya está trazado, solo hace falta encontrarlo.

Al margen de respuestas un tanto crípticas, como la que describe a la verdad como un brote tierno que debe protegerse con las espinas de una dialéctica fraudulenta, la lógica del nyāya defendió estas prácticas por varias razones. Una de ellas aducía que la razón justificada y verdadera puede en ocasiones no hallarse disponible o al alcance del que debate, de modo que este podría ponerse nervioso y no dar con ella en el momento de probar su tesis. Ante semejante crisis, utilizará algunos trucos para salir del paso. Si su oponente carece de la pericia suficiente para desenmascarar esas falacias, el naiyāyika ganará algo de tiempo para dar con la razón justa, incluso podría llegar a vencer sin haberla hallado, y la semilla del verdadero conocimiento quedaría protegida.

Otro argumento que justificaba la destreza en artimañas y trucos, propuesto por Uddyotakara, es que el conocimiento de los mismos permitirá al naiyāyika reconocerlos en el discurso de su adversario y si logra identificarlos ante el jurado saldrá vencedor. También pueden servir como salida desesperada. Cuando la derrota es inminente, uno de estos trucos puede crear la duda en el oponente y, aunque vencido, el naiyāyika se llevará la satisfacción de haber creado una duda en el vencedor. La retórica, según esta escuela, no alcanza la verdad de la lógica, pero puede protegerla. Otras escuelas, como el madhyamaka o el vedānta, verían con ironía dicha verdad de la lógica, arguyendo que no es sino el resultado de un acuerdo, siempre provisional, entre los hombres, concretamente entre aquellos que establecían las reglas y directrices que dirimían el resultado de los debates, aquellos que los convocaban y los que en ellos participaban.

\section{Argumentación negativa}

Aunque la argumentación negativa, vitạ̣dā, no debería confundirse con el escepticismo, esta forma del debate unió al mādhyamika (budista) con el materialista (cārvaka) y, más tarde, con el vedāntin (hin- 
duista). Se basa en una desconfianza fundamental hacia el lenguaje y su capacidad para confundirnos. Establece la verdad, de manera irónica, mediante una vía negativa que aparta el velo del error, que es el velo de las palabras, y se escabulle de la literalidad (de lo que las palabras significan para la gente común) para que la verdad se manifieste, si esto es posible, desprovista de palabras, aunque al mismo tiempo se reconoce la necesidad de las palabras mismas para producir esa aparición.

¿Por qué buscar lo falso? ¿Por qué desarrollar un olfato para la contradicción? ¿Por qué algunos pensadores creyeron que las palabras sirven a lo que no es el caso? ¿De qué modo, en estos estadios antiguos del pensamiento, se pensó la negatividad del lenguaje? ¿Por qué pensar contra las palabras y no del lado de las palabras? Una de las respuestas a estas preguntas consistirá en decir que esa negatividad va acotando la verdad, va clausurando los desvíos que nos alejan de ella. Si bien esa vía negativa estaba dotada de cierto escepticismo respecto a las posibilidades de lo discursivo, los que la promulgaban no creían que no existiera una verdad, sino que consideraban que las palabras no podían dar cuenta de ella, que confundían la búsqueda de quien confiaba en ellas. Llamaré a esta actitud dialéctica de lo inefable. Según esta, aunque las palabras no pueden acertar con la verdad o localizarla, sí pueden resultar útiles para cercarla, acotarla y facilitar así una intuición no verbal de ella. Como si el negar pudiera parcelar la verdad, situarla señalando donde no está, donde no hay que buscarla. De modo que esta actividad del razonamiento, que aquí toma la forma de un desmentir o refutar, sirve de vehículo (escalera o balsa fueron las metáforas budistas) para alcanzar ese lugar donde es posible la intuición de la verdad.

Parecería a primera vista que estas prácticas dialécticas, este arte del desmentir, rechazara la prescripción budista de silencio. Nada más lejos de la intuición de mädhyamika. Otro texto, el Diálogo con Vimalakīti da cuenta de esta paradoja. Los budas no se apegan a las palabras, pero tampoco tienen miedo de ellas. Que el sabio no se apegue a las palabras no significa que deba permanecer en silencio sino que está libre de las construcciones mentales asociadas con ellas. No temer a las palabras significa lograr que estas se abran a su silencio, significa poner en escena el gesto que restituya al lenguaje a lo inexpresado. 
Esta dialéctica de lo inefable, en muchas de sus formas (no solo budistas), tiene una actitud ambigua hacia el lenguaje y el razonamiento lógico. Por un lado reconoce su incompetencia para dar testimonio de la verdad, para expresar lo que, en su propia naturaleza, es inefable, y en ese sentido desconfía de él. Por el otro, esas sospechas no llegan a convertirse en un rechazo del lenguaje, pues hay una conciencia muy clara de que tanto el lenguaje como el razonamiento son herramientas indispensables para avanzar en el camino hacia el despertar.

Tanto el madhyamaka budista como el vedānta hinduista comparten esa dialéctica de lo inefable. Ambas tradiciones utilizan el lenguaje con maestría y explotan, hasta límites insospechados, las capacidades de lo discursivo (tanto lógicas como poéticas). Hay aquí un punto de contacto entre filosofía y poesía, de modo que podemos encontrar autores como Śrīharșa o Dharmakīrti que fueron célebres como poetas y como lógicos, algo no poco frecuente en la literatura de India. ${ }^{2}$

Pero, ¿qué significa hacer llegar un mensaje mediante la argumentación negativa (vitaṇdā)? Tanto Nāgārjuna como otros vitandines después de él trataron de exponer la verdad (tatva) sin hablar de ella, enfatizando una idea recurrente en el mahāyāna: la de que el Buda no pronunció palabra alguna durante su ministerio. El vitandín propone el carecer de puntos de vista como el único punto de vista que expresa el significado del despertar. La pregunta será entonces qué tipo de actitud intelectual y moral debería seguirse de esa ausencia de puntos de vista.

La vacuidad del budista es una crítica de lo convencional y en ese sentido es una crítica del debate mismo y de la propia discusión razonada. ¿Por qué entonces participar en él? ¿Por qué esa pulsión de refutación? La respuesta de los propios vitandines fue que ellos no pretendían descartar o suplantar esa realidad convencional. Sin esa realidad convencional, sin la realidad misma de las palabras y del lenguaje, la vacuidad no sería posible. La vacuidad está condicionada por ella, es, en rea-

${ }^{2}$ Considero que utilizar la palabra "mística" en este contexto lleva a confusión, si por mística entendemos la búsqueda o la existencia de una experiencia que no está condicionada por lo lingüístico, lo histórico y lo conceptual. La cuestión es si debemos conservar o no la palabra en el contexto de la filosofía temprana de la India y cómo deberíamos definirla si lo hacemos. Personalmente creo que es mejor evitarla. 
lidad, resultado de ella, causa y efecto del lenguaje mismo. De ahí que no pueda entenderse al margen de lo convencional (vyavahära), pues descansa en el mismo acuerdo humano y en ese sentido la vacuidad necesita de la objetividad (la capacidad de ponernos de acuerdo, según Rorty). Esa realidad convencional que podríamos llamar lenguaje, pero que también es conocimiento y voluntad de dominación, es el conjunto de todas las visiones del mundo, de todas las formas de imaginar lo que el mundo es, de todas las elaboraciones del lenguaje de la lógica y de cualquier otro lenguaje. De todas ellas hay un punto de vista, reflexivo, irónico, que permite ver al resto de las visiones y a sí misma como vacías. Ella misma es vacía porque no podría existir al margen de la realidad convencional, porque no puede salir del todo de sus límites, porque está condicionada, como el resto de las cosas. El vitandín trata así de imprimir, mediante su argumentación negativa, una imagen (la visión del dharma), que pudiera expresar lo que las palabras no pueden expresar, en un intento de revelar, en un sentido fotográfico, el pensamiento del despertar mediante el negativo de lo verbal.

Si algunos vitandines como Nāgārjuna o Śrī Harṣa, que pertenecían a comunidades escolásticas y religiosas que aceptaban todo un conjunto de verdades doctrinales, renunciaron a probar y se dedicaron exclusivamente a refutar entonces, como apuntó un antiguo naiyāyika de nombre Sānātani, habría que distinguir cuatro tipos de debate: $v \bar{a} d a, v \bar{a} d a-$ vitaṇ̂a, jalpa y jalpa-vitaṇ̂ă. La vieja taxonomía del nyāya necesita redefinirse, así como la misma palabra vitanda, que empieza a dejar de considerarse despectiva. El nombre de Sānātani aparece en un trabajo de Udayana (975-1050) titulado Tātparya-pariśuddhi. Probablemente fue el autor de un comentario al capítulo quinto de los Nyāya-sūtra (Matilal, 92). Según Sānātani tendría que haber cuatro tipos de debates en lugar de los habituales tres de la literatura canónica. Los dos primeros serían protocolos de una sincera búsqueda de la verdad (por ambas partes, al margen del acuerdo sobre la cuestión de si esa verdad podría expresarse mediante palabras o argumentos), mientras que los segundos solo perseguirían el prestigio de la influencia. En los dos primeros hay una voluntad de saber, aunque en el caso del vitandín ese saber no sea discursivo, en los segundos una voluntad de poder. Considero importante la configuración de esta taxonomía en la India antigua porque 
es precursora del tema de nuestro tiempo, apuntado por Nietzsche y desarrollado por Foucault, la relación entre conocimiento y poder. La distinción que Udayana atribuye a Sānātani pone su énfasis en el poder de la verdad y descuida esa otra de la verdad del poder.

La ocurrencia de un error lógico en el debate, de una falacia o una contradicción, que significaría la derrota inmediata, es función de su detección por el oponente o por el juez. Un error que pasa desapercibido es tan bueno como una verdadera razón. La idea es que para hablar de $r a-$ zón (y distinguirla de falacia) tenemos que movernos dentro de un orden, en este caso el orden establecido por las reglas del debate, pero cuando hablamos del razonamiento y del lenguaje, ese orden no es nunca un orden completamente cerrado (las conversaciones y los debates siguen teniendo lugar, la lengua sigue viva). Uno puede tener razón, digamos, en un sudoku, donde la inteligencia trabaja sobre un orden subyacente, un orden completo en el que hay aciertos y errores. Si nos desplazamos a un juego como el ajedrez, localizar el acierto y el error resulta ya más complicado, pues será en función de cómo se haya desarrollado la partida que se considerará un movimiento particular un acierto o un error. La razón se decidirá cuando la partida haya concluido, cuando Aquiles haya alcanzado finalmente a la tortuga, cosa a priori imposible. Lo mismo sucede, según Śrī Harṣa, en un debate y algo parecido ocurre en la historia, que quita la razón a unos y la otorga a otros que en vida nunca la tuvieron.

\section{Vigencia del vitandín}

La historia de las ideas, que Foucault ha sabido esbozar de modo tan perspicaz, muestra cómo el rechazo de ciertos vocabularios ha ido configurando los diferentes escenarios en la batalla por el estatuto de lo verdadero. Pero toda crítica del lenguaje, hoy lo sabemos bien, es crítica de un cierto lenguaje. No importa que esta se presente a sí misma como una crítica del lenguaje en su totalidad: siempre acaba por proponer un vocabulario que ocupe el lugar del socavado. Los vitandines criticaron el lenguaje de la lógica para sustituirlo por toda una serie de metáforas de la ilusión, pero la originalidad de su propuesta consiste en haber tenido una conciencia muy clara de que al heredar el lenguaje heredamos 
las incontables palabras pronunciadas por los hombres, razonables o insensatas, filosóficas o poéticas, palabras que hemos de cargar, palabras que dieron cuerpo a un sentido que cae sobre nosotros, conduce nuestra ceguera y dirige nuestro ánimo.

La tarea del vitandín, con frecuencia acusado de escéptico, desplazada por la ciencia autorizada de la lógica (nyāya), transforma la lógica y sus resultados en el sueño dogmático de un mundo encantado. Pero lejos de parapetarse en una "razón del prodigio", el vitandín reconoce en todo discurso sobre la verdad la servidumbre a estructuras lingüísticas, históricas y culturales: el sánscrito, el uso de ciertos procedimientos y vocabularios, siempre amenazados por su fecha de caducidad, las distinciones fósiles o innovadoras, etc. Escenificando, en su ironía, que esa misma lógica es un efecto de lo convencional, del acuerdo mutuo, un efecto, en definitiva, de un lenguaje siempre provisional. Tras lo que se dice en los debates no hay nada, nada que decir que no sean otros dichos. La autoridad de la lógica no descansa pues en una conexión privilegiada con los hechos del mundo, sino que es un efecto más de lo social, del lenguaje y de la capacidad de ponernos de acuerdo.

Es en los supuestos a los que aludimos constantemente donde descansa el sentido de lo que decimos (compartir lo tácito es entenderse, no hacerlo es hablar lenguajes diferentes). De modo que el sentido está siempre en suspenso, en un afuera, nunca completamente expuesto. ${ }^{3}$ Así, toda pretensión de soberanía de lo explícito, el argumento de-mostrado en el debate, oculta la realidad del sentido que presume: las reglas y acuerdos provisionales que lo hacen posible. La risa es un buen ejemplo de cómo el sentido habita lo tácito. Vayamos al cine o al teatro en Asia, observemos las reacciones del público y nuestra propia reacción. Comprobaremos rápidamente que cuando otros estallan en carcajadas, nosotros enmudecemos y viceversa. No importa si la película es asiática o europea, la falta de sintonía se hará en seguida evidente. Lo explícito, lo que vemos en la pantalla, tiene sentidos diferentes debido a lo que no se ve, lo implícito.

Dado que para el vitandín el sentido no puede reducirse a lo explícito, la ironía le servirá de antídoto para contrarrestar esa tendencia general

${ }^{3}$ De ahí su parentesco con el poeta, si entendemos la poesía, siguiendo a Paul Celan, como "aquello que sin imponerse, se expone". 
(y dominante) del pensamiento a ocultar lo que le sirve de base, que ha sido y sigue siendo una de sus estrategias para preservar su autoridad. ${ }^{4}$

Esta idea, ahora que la filosofía ha logrado por fin parodiarse a sí misma, tiene una rabiosa actualidad. Hoy sabemos bien, gracias a Gadamer, Rorty y otros héroes del giro lingüistico, que las suposiciones que utilizamos al conversar o al debatir, lo que damos por sentado, son exteriores al discurso explícito y que la efectividad del propio discurso descansa precisamente en su capacidad de mantener al margen todos los supuestos que arrastra. Hoy sabemos que muchas veces lo que nos convence es, precisamente, lo que no se dice, lo que, desde su silencio, habla. Y esa "exterioridad", ese afuera, no es independiente del lenguaje y de los acuerdos tácitos que negocia cada cultura, acuerdos que tienen a su vez una naturaleza histórica y cuya transformación es función de conversaciones y debates. De modo que se podría decir, como ha apuntado José Luis Pardo (141), que es el curso mismo de la conversación (o de la batalla dialéctica) lo que va creando el terreno sobre el que se mueven los hablantes. Esto podría explicar porqué los vitandines, sin pretender probar nada, se empeñaron en no ser excluidos del ágora del debate. Convirtiéndose en representantes de una escuela cuyo manifiesto ignoraban, mediante un estilo que huía de la certeza y promovía el asombro mediante la práctica social de la lógica.

La miseria de la filosofí, tema de nuestro tiempo, fue para ellos más bien una parodia y un teatro para la ironía (y muchas veces la vanidad, los vitandines, no lo olvidemos, eran temidos y admirados por su maestría en la refutación). Como el poeta, el vitandín solo pretende mostrar, rehusando demostrar. Se ve a sí mismo, en su ironía, dedicado pacientemente a la refutación, en la creencia de que el lenguaje, en su soberanía negativa, tendrá el poder de hacer aparecer el cuerpo visible y eterno de la verdad a quien sepa escuchar su silencio. ${ }^{5}$

${ }^{4}$ La lógica habla y se desarrolla como si no se sustentara en axiomas, manteniéndolos fuera de la discusión. Si en la lengua viva el sentido de lo dicho está siempre pendiente de los hablantes, la tarea del vitandín consistirá en sacarlo a la luz sin fosilizarlo mediante el concepto.

${ }^{5}$ Veamos ejemplos de conflicto entre vocabularios en las disciplinas científicas contemporáneas. Supongamos que nos iniciamos, por ejemplo, en el estudio de la materia. En primer lugar nos veremos obligados a familiarizarnos con todo un vocabulario heredado de esa tradición de conocimiento, un vocabulario que habla de átomos, proto- 
Los vitandines comprendieron muy bien, en su insumisión a la lógica (una insumisión que no impedía una práctica continua de la lógica), que entre los pliegues de la filosofía, entre los surcos dejados por el razonamiento, se puede advertir un sesgo poético. Su mirada advirtió perspicaz que no hay nada tan filosófico como las limitaciones de la filosofía y que la filosofía, en su intento desesperado, y a veces ridículo, de dar cuenta de lo real, guarda un estrecho parentesco con el teatro.

\section{Teatro de la lógica}

Si el teatro es el ejercicio, eficaz y lujoso, del absurdo (Cortázar) ¿qué significa sugerir, como hizo Nāgārjuna, que la lógica sea un teatro? Una

nes, electrones, campos magnéticos, partículas elementales, campos de fuerza, ondas de probabilidad, números cuánticos, etc. $\mathrm{Y}$ estas palabras nos ayudan a crear un universo de significado (relaciones) en el que habitan las entidades (identidades) citadas. Y hablar de la materia es hablar en estos términos.

Nos iniciamos en el estudio de la vida y, de nuevo, nos encontramos (heredado de la tradición) con un vocabulario que habla de células, proteínas, nutrientes, neurotransmisores, genes, ADN, etc. Y estas palabras nos ayudan a crear un universo de significado (relaciones) en el que habitan todas estas entidades (identidades). Y hablar de la vida es hablar en estos términos.

Iniciamos el estudio de la mente y el comportamiento y nos encontramos (heredado de la tradición) con un vocabulario que habla de neurosis, paranoias, esquizofrenias, placebos, frustraciones, etc. Y esas palabras nos sirven para crear un universo de significado en el que habitan todas las entidades (identidades) citadas. Y hablar de la mente es hablar en esos términos.

Y ocurre, cuando nos disponemos a elaborar un discurso sobre la materia, la mente y la vida, que los vocabularios de los que disponemos son inconmensurables entre sí. Podemos hablar de las proteínas de la célula, pero no nos es lícito hablar de la función de ondas de las partículas que componen la célula o de la neurosis de la célula (y si lo hacemos nuestro discurso ya no es científico, sino poético). De modo que las diferentes disciplinas de conocimiento entablan un diálogo de sordos, establecen las condiciones mismas para un solipsismo epistémico. Hay aquí una falta de entendimiento, falta un traductor. Incomunicadas, sordas hacia lo que dicen las otras, las ciencias avanzan como si la neurosis no tuviera que ver con la vida o las células no fueran materia.

Hablar muchos de estos idiomas, ¿nos llevará a un mejor entendimiento del mundo? ¿O simplemente nos puede ayudar (lo que no es poco) a encontrar las brechas de un determinado lenguaje gracias al conocimiento del otro? Conocer varios de estos lenguajes puede ayudar a perfeccionarlos, pero deja sin respuesta la cuestión principal, el entendimiento entre ellos. 
de las posibles justificaciones de la metáfora, sugerida por Jesús Aguado, sería considerar que la lógica, como el teatro, tiene una tramoya. En ella se urden prodigiosos efectos, de modo que mostrar esa maquinaria de la transformación es una manera de desmontar la ilusión colectiva del pensamiento. Pero hay otra posible respuesta, más cáustica y más política, a esa actitud: la tramoya es también el enredo dispuesto con ingenio, disimulo y maña, una de las estrategias clásicas del poder, cuya metáfora es, precisamente, el teatro. El teatro tiene un antepasado respetable en India, el ritual. De las relaciones entre ritual, teatro y lógica se ocuparán estas páginas, que son un intento de rastrear posibles antecedentes de tan célebre filósofo.

Si nos atenemos a la primera posibilidad, el desmontaje de la ilusión colectiva del pensamiento, iniciativa que tiene su paralelo en el movimiento deconstruccionista moderno, la pregunta sería entonces a qué propósito sirve esa labor de desencantamiento. Una de las posibles respuestas fue esbozada en La palabra frente al vacio, publicado en México hace ya cuatro años. En esa dirección se publicaron más tarde (en la introducción y el epílogo a la edición crítica de Abandono de la discusión, otra de las obras importantes de Nāgārjuna) algunas reflexiones que pudieran acercarnos a la utilidad, para la vida, para la mente, para la solidaridad, de la doctrina del vacío.

La segunda posibilidad plantea la cuestión de la lógica como estrategia de poder. Para que la lógica conserve su capacidad de convicción es necesaria cierta distancia. Algo parecido ocurre con las disciplinas científicas, su poder persuasivo radica precisamente en su secreto. El laboratorio solo es público para una cierta comunidad de investigadores, de iniciados, y sus efectos solo resultan maravillosos si se contemplan desde fuera. En las humanidades ocurre algo bien distinto (aunque la opacidad y el enmascaramiento no siempre están ausentes), el individuo es sujeto y objeto, observador observado, investigador y objeto de la investigación (en ese sentido la física cuántica, en la que el experimento absorbe al observador, es muy humana). En ellas se admite implícitamente que el hombre, la vida y la naturaleza solo pueden conocerse desde dentro, desde su habitual inmanencia, desde un natural compromiso (somos jueces y parte) con aquello que hemos elegido como "objeto" de investigación. Wittgenstein decía que solo podríamos acceder 
al conocimiento del mundo si, como el Dios de las religiones del Libro, fuéramos capaces de verlo desde fuera, desde la trascendencia del que no se ensucia las manos a la hora de poner en marcha el mundo, desde la distancia del que no se compromete, en una comunidad de destinación, con aquello que pretende conocer.

El laboratorio evita esa implicación mediante aparatosos instrumentos, que crean la distancia necesaria para la objetividad, mientras que en el teatro esa distancia la marca la separación entre el escenario (con su tramoya oculta) y la platea que ocupan los espectadores. Y de esta manera parece, a la mirada ingenua, que es posible (y necesario) estar fuera del fenómeno, mantenerse a distancia, observarlo sin contaminarlo. Esa falta de implicación es precisamente la que sirve de justificación a la neutralidad. ¿Cómo podría estar una máquina inclinada, debido a impulsos inconscientes o pasiones latentes, a adoptar un determinado sesgo en la observación del fenómeno? La máquina/tramoya no miente, no pueden sentirse frustrada o apasionada, suya es la imparcialidad del cálculo, la verdad de lo inerte. Lúgubre conocimiento.

El vitandín rechaza la verdad de ese secreto y hace de puente, de cómplice, entre la escena y el público, entre lo inmanente y lo trascendente, entre el actor y el espectador, es como uno de esos personajes de las comedias del teatro clásico que se dirigen al público con sus apartes, anticipando mediante un susurro algunos de los secretos que la acción dramática irá desvelando. Su actitud nos plantea numerosas cuestiones, la primera de todas, la más ineludible sería la siguiente: ¿Es posible consagrarse a la lógica, entrenarse pacientemente en sus jugadas, aprender sus movimientos más gráciles, conjugar sus formas más sutiles y, al mismo tiempo (o por eso mismo), desconfiar de sus posibilidades y recelar de sus resultados? ¿Se puede practicar la lógica sin creer en ella? ¿O es precisamente ese escepticismo el que da sentido y hace posible su práctica? ¿Está, en definitiva, toda lógica destinada a la representación, irónica o teatral? Siendo así, ¿traiciona el mādhyamika a sus colegas lógicos? ¿Está justificada su expulsión de los debates públicos? (intentos de los que tenemos constancia en la literatura antigua de India). ¿Por qué entonces no retirarse, por qué no abandonar la discusión, por qué su empeño de seguir participando, de manera irónica, en los debates? 
La impresión que uno tiene cuando trata de entender el propósito de estos abogados del diablo es que en su escenificación del absurdo (recordemos que la tarea del prāsangika consistía en reducir al absurdo las proposiciones de sus oponentes), el mädhyamika es muy consciente de que la lógica, como la sinfonía, el ritual o la obra de teatro, no es nada sin su ejecución. Su liturgia se realiza, convertida en res, solamente al ser ejecutada. Esa res, esa "cosa" sobre la que trabaja el mädhyamika, es una impresión, una marca, una sensación. Una impresión que, como toda impresión, no puede decirse, no puede demostrarse. Y la mosca se queda en la oreja, murmurando las limitaciones de la lógica y la necesidad de un afuera, como mostró Gödel en su célebre teorema. De modo que el espectador queda incorporado a la escena, impelido a seguir trabajando, a ser lógico sin idealizar la lógica, a ejecutarla como propedéutica, como camino, como inteligencia de la vida humana, como cultivo de la mente para la realización de los fines budistas: contemplar el samsāra desde un lugar donde el sufrimiento ya no es posible.

Como ya se dijo, el mādhyamika practica el debate tipo vitandăa que es un debate de refutación. Para que se pudieran dar este tipo de debates una de las partes establecía una tesis, mientras que la otra se encargaba de refutarla sin proponer tesis alguna. Una de las formas más habituales de llevar a cabo la argumentación negativa fue la reducción al absurdo (prasanga). El mādhyamika asumía provisionalmente (abhyupagama), los supuestos o axiomas del adversario. Una vez asumidos, los desarrollaba siguiendo las reglas de la lógica del oponente, mediante el uso de inferencias (anumāna), ejemplos pertinentes (upamāna) y otros medios de conocimiento (pramāna) que su interlocutor consideraba válidos. Este desarrollo continuaba hasta alcanzar una proposición que contradijera los supuestos (los axiomas de partida) del adversario. Su trabajo dialéctico tenía como objetivo final el absurdo y no la conclusión válida. Se ha dicho a menudo que el sentido es algo que se construye. En este caso el absurdo también lo sería. Ambos requieren de la lógica.

La reducción al absurdo, muy utilizada hoy día en el análisis matemático, ha sido una estrategia frecuente en filosofía, de modo que si definiéramos la práctica filosófica en función de sus métodos (y no en función de las creencias de aquellos que los emplean), estas prácticas dialécticas deberían encuadrarse en el ámbito de lo que hoy llamamos 
filosofía. Pero hay algunas diferencias entre lo que hace el matemático y lo que hace el mādhyamika. El matemático, para probar una ecuación, supone lo contrario, transformando la igualdad que quiere probar en desigualdad. A continuación se desarrolla esa desigualdad hasta dar con una contradicción. Una vez encontrada, se considera probada la equivalencia primera. Para el mādhyamika este procedimiento tampoco es lícito. Probar que algo es lógicamente contradictorio no tiene por qué implicar que su contrario sea cierto. Reducir al absurdo una creencia no tiene por qué implicar su contraria, puede simplemente significar el rechazo mismo de los términos en los cuales se formula dicha creencia (en términos de la lógica, el rechazo de los axiomas). Reducir al absurdo la idea de que el universo es una creación divina no tiene por qué implicar que ha sido creado por un demiurgo, bien pudiera ser que el universo nunca hubiera sido creado. Siguiendo el hilo que marca el ejemplo podríamos decir que el mādhyamika rechaza la terminología creativa (la noción de origen), sin que eso quiera decir que se acepte otro tipo de terminología, pues sospecha (sin que sea fácil decir cómo) que las palabras crean un velo (el velo de $m \bar{a} y \bar{a}$ ), que impide ver las cosas tal y como son, y su rechazo, que difiere la solución indefinidamente, se extiende (se disemina) a todo concepto. ${ }^{6}$ Uno podría preguntarse si la búsqueda del absurdo puede ser un objetivo legítimo de la filosofía. Los mädhyamika, precursores de la filosofía del absurdo de Albert Camus, pensaban que sí. Algunas voces contrarias argumentaron $\mathrm{y}$ argumentan que la contradicción no puede ser el objetivo de la filosofía, pues la filosofía misma es el esfuerzo por neutralizar el absurdo y, así, dar sentido al mundo.

Los vocabularios que afirmaron o censuraron esta actitud alcanzarían un alto grado de violencia intelectual. Para contrarrestar dicha agresividad, los jainistas extendieron su doctrina de la no violencia a la argumentación filosófica, estableciendo que toda crítica debía ser precedida de una comprensión total y profunda de la doctrina a rebatir. Mediante dicha asimilación se neutralizarían los efectos nocivos que la crítica des-

\footnotetext{
${ }^{6}$ Esa crítica del lenguaje se resuelve, como ocurre a menudo, en crítica de un cierto lenguaje, que termina por sustituirse por otro lenguaje, en el caso del mädhyamika por toda una serie de metáforas de la ilusión.
} 
pierta en el ánimo (ya en el que la ejerce o en el que la sufre). Esta doctrina, llamada anekāntavāda ("la verdad no está solo en un lado"), fue una de las más grandes manifestaciones de la tolerancia intelectual de la historia de la filosofía india (Pániker, 372).

Otros vieron en la estrategia del mādhyamika una labor de desbrozado. La reducción al absurdo y la argumentación negativa no pueden decirnos lo que el mundo es o cuál es la verdad, pero sí pueden preparar el camino para que esa verdad se manifieste por sí misma. Como si para escuchar la música de la verdad hubiera que silenciar el susurro del lenguaje.

Es bien conocida la incapacidad de las palabras para dar cuenta de muchas de las vivencias que experimentamos cada día. Wittgenstein proponía que tratáramos de describir el sonido de un clarinete, Chesterton los colores de una selva otoñal. Pero esa torpeza del lenguaje se confunde a menudo con la futilidad de las palabras o de la lógica, en aras, en general, de una experiencia más allá del lenguaje, como si esa misma experiencia fuera algo extraordinario. ¿Existe acaso algún tipo de experiencia que no esté más allá del lenguaje? Lo que puede enseñarnos el uso que hicieron los mädhyamika de la lógica es, precisamente, que el razonamiento puede servir muy bien de base a la intuición de la negatividad del lenguaje, un tema recurrente de la filosofía reciente (pienso en Saussure, Derrida, Adorno y Agamben) y que los gramáticos indios abordaron mediante el concepto de apoha. ${ }^{7}$

Hay unos versos del Rgveda que seguramente resultarían deliciosos para el vitandín, se encuentra en el libro primero y dicen así: " $n a v i$ jānāmi yadivedām asmi nịyah partaking ṃnaddho manasā carāmi”, lo que se podría traducir como: "No sé muy bien qué hago aquí, perplejo y

${ }^{7}$ La escuela de Dignāga, el vijñānavāda o yogācāra, desarrolló, para apoyar su concepción inmaterialista del mundo, el concepto de apoha. El término, de reminiscencias nominalistas, literalmente significa exclusión o diferenciación. Para el vijñānavāda las palabras son la consecuencia de la conceptualización y por lo tanto, en su abstracción, aunque tengan su origen en la percepción, no pueden asociarse directamente con realidades externas. La teoría distingue la palabra, como instrumento de un acto de referencia, del referente mismo, el objeto exterior, lo que le concede una independencia respecto al mundo exterior que no solo hace posible la conciencia, sino que la convierte en el actor principal en la creación de mundos de significado que gozan de cierta autonomía respecto al mundo exterior. 
atado a una mente" (Rgveda I 164.37). Ese afecto al asombro y la inquisición reaparece en otro himno, el de la creación (Nāsadìya, X, 129), quizá el más celebrado de este antiquísimo poema. En él se barajan las posibles causas del origen del mundo.

Entonces no había lo existente ni lo inexistente; no había espacio ni cielos más allá. ¿Qué era lo latente? ¿Dónde? ¿Quién lo protegía? ¿Quién puede decirnos de dónde y cómo surgió este universo? Los dioses son posteriores a este comienzo. ¿Quién conocerá entonces el origen de la creación? Quizá surgió de sí mismo, o quizá no, solo el que ve desde el cielo más elevado lo sabe. O quizá tampoco Él lo sabe (Rgveda X, 129).

Quizá Él tampoco lo sabe, quizá la trascendencia carezca de sentido lógico y solo haya inmanencia, quizá. Y sin embargo el vitandín nos remite al afuera, lo hace posible. Los hombres vivimos en función de los significados que hemos de inventar, esos significados no solo reflejan o aproximan un mundo independiente de nosotros, sino que participan en su propia construcción. Como señala Rappaport en su obra enciclopédica sobre el ritual:

Los mundos en los que viven los humanos no están formados únicamente por procesos tectónicos, meteorológicos y orgánicos. No solo están hechos de rocas, árboles y océanos, sino que también están constituidos por cosmologías, instituciones, reglas y valores concebidos simbólicamente y determinados mediante expresiones performativas. Con el lenguaje el mundo comienza a proveerse de cualidades como lo bueno y lo malo, abstracciones como democracia y comunismo, valores como honor, valentía y generosidad, seres fabulosos como demonios, fantasmas y dioses, lugares imaginarios como cielo e infierno. Todos estos conceptos se reifican, se convierten en res, "cosas" reales, mediante las acciones sociales que dependen del lenguaje (Ritual y religión en la formación de la humanidad).

Es esa participación performativa del vitandín en los debates la que pone al descubierto esos lugares imaginarios, que pueden tomar la forma de una diablesa o de una conclusión.

Los procedimientos lógicos más antiguos que encontramos en las tradiciones indias se refieren precisamente al ritual. Pero si bien es cier- 
to que el ritual posee ya, como estructura que establece relaciones entre un cierto número de elementos, ciertas propiedades lógicas, esa lógica no es meramente una lógica y el modo en el que se percibe no se limita exclusivamente a lo especulativo. Sin embargo, hay ciertos elementos del ritual que sí pueden considerarse como los primeros esbozos registrados del pensamiento especulativo. Se trata de la práctica sacerdotal de plantear enigmas durante la ejecución del ritual védico. Estos enunciados performativos (aquellos que no se limitan a describir un hecho sino que por el mismo hecho de ser expresados realizan el hecho) procedían seguramente de tradiciones orales, narrativas míticas y leyendas, y tomaban la forma de acertijos o adivinanzas. Uno de los más célebres aparece en el Yajurveda blanco:

Te pregunto por el límite de la tierra, te pregunto por el ombligo del mundo, te pregunto por el semen del caballo, te pregunto por la bóveda más alta del lenguaje.

El límite de la tierra es este altar, el ombligo del mundo este ritual, el semen del caballo este soma y la más alta bóveda del lenguaje es brahman.

Aunque tuvieran su origen en el imaginario popular y las narrativas orales, los acertijos pasaron a formar parte de diferentes ceremonias del ritual védico, como el sacrificio del caballo (aśvamedha), el sacrificio real (rājasūya) y el sacrificio del soma (vājapeya). En dicho contexto fueron llamados brahmodya o brahmavādya, pues su naturaleza especulativa tenía como objeto el brạman, aunque muchos de ellos trataban otros temas: fenómenos naturales y atmosféricos, asuntos de la vida religiosa o cuestiones cosmológicas. Aparecen numerosas referencias a ellos en la literatura ritual de los brăḥmaṇa (Sternbach, Indian Riddles).

La utilización de acertijos en el ámbito religioso no se limita a la India (Huizinga, 172). También los encontramos en el zoroastrismo del Avesta, en la tradición judía (Libro de Job), en la literatura china con Lao-Tzu y en el Chuang-Tzu y en las tradiciones escandinavas. Estos acertijos de naturaleza religiosa o teológica vivificaban con sus efectos la rutina del ritual mediante una suerte de pirotecnia intelectual (Bloomfield, 215). 
La interpretación ritual del brạ̣modya era llevada a cabo por dos sacerdotes (el Hotar y el Adhvaryu), uno de los cuales formulaba los acertijos y otro los respondía de memoria, a veces de manera inmediata, otras alternando preguntas y respuestas, pero siempre a gran velocidad, lo que producía el asombro de la congregación. La referencia a los temas de dichos intercambios performativos no es directa, en su formulación se utiliza un simbolismo solo accesible al iniciado. De modo que el asunto mismo de la inquisición es ya un enigma, como lo será su respuesta.

El acertijo lleva implícito el acierto. El acierto es anterior y el acertijo lo dramatiza. Su pregunta tiene ya una respuesta y el acertijo pone en escena (representa) el proceso mismo de su sorprendente aparición. El intercambio veloz de acertijos entre los sacerdotes del ritual védico dramatiza un debate intelectual, pone en escena una búsqueda de la verdad, pero lo que en realidad está haciendo es establecer toda una serie de correspondencias y equivalencias, toda una serie de juicios analíticos y normativos. Estas equivalencias pueden ser entre lo abstracto (nombres de dioses, por ejemplo) y elementos de la experiencia cotidiana, de modo que se van definiendo los términos en los que ha de establecerse la especulación filosófica. Parecen una polémica, pero son un diccionario o una tabla de leyes. Así, la práctica social del ritual sienta las bases (va estableciendo los términos) del pensamiento especulativo. Va creando la objetividad (que es la capacidad de ponernos de acuerdo, fundamentalmente en el lenguaje que utilizamos y sus reglas) y configurando el saber.

Los acertijos funcionan como tautologías, son siempre verdaderos (la tradición lo atestigua). En lógica se llama tautología a las fórmulas que son siempre verdaderas independientemente de cual sea el valor de verdad de los elementos que la componen. ${ }^{8}$ Es un equivalente a lo que Kant, siguiendo a Leibniz, llamaba juicios analíticos. Las cuestiones sobre la naturaleza de la tautología han sido ampliamente debatidas en la lógica contemporánea. Una de las posiciones más discutidas (hoy rechazada) es la de Wittgenstein, según la cual las matemáticas puras, incluida la

${ }^{8}$ Las tautologías pueden ser de muy diversos tipos: leyes de identidad, contradicción y tercio excluido, la ley de la doble negación y las leyes de conmutación y distribución (Ferrater Mora, Diccionario de filosofía). 
lógica, constan exclusivamente de tautologías (Tractatus, 6.1, 6.22.). Según Wittgenstein una proposición muestra lo que dice, mientras que la tautología y la contradicción muestran que no dicen nada. De ahí que la tautología no tenga "condiciones de verdad" y sea "incondicionalmente verdadera" (y la contradicción "incondicionalmente falsa"). Pero el hecho de que la tautología carezca de sentido no quiere decir que sea absurda (lo mismo ocurre con la contradicción). La tautología pertenece, según Wittgenstein, al simbolismo, de una forma análoga a como el número 0 pertenece a la simbología de la aritmética. De ahí que ni la tautología ni la contradicción sean descripciones de la realidad.

Aristóteles dice en el capítulo cuarto de su Poética que tanto la tragedia como la comedia surgieron a partir del ritual y más concretamente del Ditirambo, una celebración de primavera asociada con Dionisios. Jane Harrison advierte que la palabra "drama" viene de dromenon ("cosa hecha"), un antiguo término griego para el ritual. No es disparatado suponer que lo mismo sucedió en India.

Así, encontramos que el ritual es el lugar (espacio del contrato social, la reglas morales y el establecimiento de lo normativo y convencional) donde se forjan los vocabularios a los que recurrirán los primeros protocolos de la argumentación. Como se ha dicho, la institución de la verdad que se lleva a cabo en el ritual está relacionada con la del teatro en el sentido de que ambos son performativos, sin embargo, la eficacia del ritual reside precisamente en su capacidad de transformar el orden social (un individuo puede salir del mismo con un estatus social diferente), algo que no ocurre en la obra de teatro, donde el espectador puede salir conmovido pero a efectos sociales es el mismo ciudadano. Esa es la diferencia entre la verdad del ritual, que presenta el orden como el buen orden, el único orden posible; y la mentira del teatro, que puede cuestionar o ridiculizar ese orden pero no puede transformarlo de manera inmediata. En el rechazo de esa distinción se sitúa la postura política del filósofo ironista. Los debates trasformaban el contrato social de manera inmediata, redistribuyendo el estatus de una comunidad o de un individuo en función de su éxito o fracaso en ellos. La verdad que salía del debate era favorecida por el rey, que otorgaba privilegios a la comunidad que sostenía la doctrina del representante dialéctico que había resultado vencedor. El mädhyamika pretende desmontar la supuesta 
diferencia entre la inmutabilidad del ritual (que no solamente es visible sino que está subrayada continuamente por sus meticulosas repeticiones, representando así lo que está codificado) y la inmutabilidad del teatro, que se mantiene oculta tras la ilusión de novedad y espontaneidad que da vida a los dilemas que representa.

Rappaport ha enumerado algunas de las diferencias entre el teatro y el ritual. Una de ellas son las relaciones de los presentes con los propios procedimientos rituales. Quienes están presentes en el ritual constituyen una congregación. La participación es el elemento clave que define el papel y el estatus de cada uno de los miembros de una comunidad en el ritual. Esa participación no se da en el teatro, donde los actores y el público se encuentran claramente diferenciados, separados mediante escenarios elevados, arcos proscénicos o cortinas. Mientras que los actores ejecutan, danzan, cantan o tocan, el público se limita a contemplar. Algo que no ocurre en la congregación, que participa de estas acciones. Sin embargo, el teatro de la lógica que nos enseña, con su ironía, el mādhyamika, exige de nuestra participación intelectual. Su actitud filosófica haría retornar la lógica (representada en los torneos dialécticos), al ámbito de un teatrum philosophicum, que comparte con el ritual la necesidad de la participación, de la complicidad, del espectador. ¿Qué habrá de seguirse entonces de esta filosofía entre bastidores? El buen orden, el único orden posible, el orden en sí mismo que representa el ritual de la lógica se presenta ahora como problemático en la representación que lleva a cabo el mādhyamika. Generalmente estamos acostumbrados a que el signo sea insustancial y lo significado sustancial, como por ejemplo en la relación entre la palabra tigre y el animal que designa. La representación irónica produce signos que son guiños, tiene como sustancia el absurdo lógico, mientras que su significado, la complicidad del espectador, es insustancial o, para decirlo de una manera más precisa, tiene una naturaleza mental. Esta inversión nos recuerda las palabras que hace ya casi un siglo pronunciara un poeta ante un auditorio de filósofos:

La mayoría de los lectores atribuye a lo que denomina el fondo una importancia superior, incluso infinitamente superior, a lo que denomina la forma. Otros hay, sin embargo, que ven las cosas de modo completa- 
mente diferente, y piensan que tal manera de juzgar es una superstición. Consideran audazmente que la estructura de la expresión está dotada de una suerte de realidad, mientras que el sentido, o la idea, no es más que una sombra. El valor de la idea no está determinado, cambia con las personas y los tiempos. Lo que uno considera profundo, para el otro es una evidencia insípida o una absurdidad insoportable. Basta, finalmente, mirar un poco en derredor para observar que lo que aún puede interesar de las letras antiguas a los modernos no pertenece al orden de los conocimientos, sino al de los ejemplos y los modelos (Paul Valéry, "Poesía y pensamiento abstracto").

\section{REFERENCIAS}

Bloomfield, Maurice, The Religion of the Veda, G.P. Putnam's Sons New York, 1908.

Ferrater Mora, José, Diccionario de filosofía, edición revisada, aumentada y actualizada por Josep-María Terricabras, Barcelona, Ariel, 1994.

Huizinga, Johan, Homo Ludens: a Study of the Play-Element in Culture, Boston, Beacon, 1950.

Matilat, Bimal Krishna, Nyāya-Vaiśeșika, Wiesbaden, Otto Harrassowitz, 1977.

PÁNIKER, Agustín, El jainismo: Historia, sociedad, filosofia y práctica, Barcelona, Kairós, 2007.

Pardo, José Luis, La metafisica. Preguntas sin respuesta y problemas sin solución, Valencia, Pre-textos, 2006.

RAPPAPORT, Roy, Ritual y religión en la formación de la humanidad, trad. Sabino Perea, Madrid, Cambridge University Press, 2001.

Sternbach, Ludwik, Indian Riddles. A Forgotten Chapter in the History of Sanskrit Literature, Hoshiarpur, Vishveshvaranand Vedic Research Institute, 1975.

VALÉRY, Paul, "Poesía y pensamiento abstracto" [conferencia pronunciada en la Universidad de Oxford], en Teoría poética y estética, trad. Carmen Santos, Madrid, Visor, 1990.

Wittgenstein, Ludwig, Tractatus Logico-Philosophicus, versión e introducción de Jacobo Muñoz e Isidoro Reguera, Madrid, Alianza, 2002. 
